\title{
A case control study on family history as a risk factor for herpes zoster and associated outcomes, Beijing, China
}

\author{
Luodan Suo ${ }^{1}$, Li Lu', Juan Li", Mu Sun², Haihong Wang ${ }^{3}$, Xinhui Peng ${ }^{4}$, Fan Yang ${ }^{1}$, Xinghuo Pang ${ }^{1}$, \\ Mona Marin ${ }^{5}$ and Chengbin Wang ${ }^{5^{*}}$ (D)
}

\begin{abstract}
Background: Hospital-based case control studies have found family history of herpes zoster (HZ) was associated with risk of $\mathrm{HZ}$, but the role of family history is not fully examined for other $\mathrm{HZ}$-associated outcomes such as recurrent $\mathrm{HZ}$, occurrence of postherpetic neuralgia (PHN), and $\mathrm{HZ}$ with different pain severities.

Methods: We conducted a population-based matched case control study. HZ cases that occurred during December 1 , 2011 to November 30, 2012 were identified by face-to-face interview with all residents of eight selected communities/ villages from three districts of Beijing, China. Medical records were reviewed for those who sought healthcare for $\mathrm{HZ}$. For each case-patient, three, age-matched controls ( \pm 5 years) without $\mathrm{HZ}$ were enrolled from the same community/ village of the matched case. Data on family history of $\mathrm{HZ}$ were collected by interview and only defined among firstdegree relatives.
\end{abstract}

Results: A total of 227 case-patients and 678 matched controls were enrolled. Case-patients were more likely to report a family history of $\mathrm{HZ}$ [odds ratio $(\mathrm{OR})=2.4, P=0.002$ ]. Compared with controls, association of family history decreased from $\mathrm{HZ}$ with $\mathrm{PHN}$ to $\mathrm{HZ}$ without $\mathrm{PHN}(\mathrm{OR}=6.0$ and 2.3, respectively; $P=0.002$ for trend), from recurrent $\mathrm{HZ}$ to primary $\mathrm{HZ}(\mathrm{OR}=9.4$ and 2.2, respectively; $P=0.005$ for trend), and from $\mathrm{HZ}$ with moderate or severe pain to $\mathrm{HZ}$ with mild or no pain ( $O R=3.2$ and 0.8 , respectively; $P<0.001$ for trend).

Conclusions: Family history of $\mathrm{HZ}$ was associated with $\mathrm{HZ}$ occurrence and was more likely in $\mathrm{HZ}$ case-patients with PHN, recurrences, and painful $\mathrm{HZ}$.

Keywords: Herpes zoster, Family history, Postherpetic neuralgia, Recurrent herpes zoster

\section{Background}

Herpes zoster (HZ) (also called shingles) is caused by the reactivation and replication of the latent varicellazoster virus (VZV) acquired during primary infection (varicella). HZ is usually characterized by unilateral, radicular pain and a vesicular rash generally limited to a single dermatome regulated by the sensory ganglion where the latent VZV reactivated. Though the rash usually heals within two to four weeks, complications from $\mathrm{HZ}$ can occur. The most common complication of $\mathrm{HZ}$ is postherpetic neuralgia $(\mathrm{PHN})$, generally defined as pain

\footnotetext{
* Correspondence: taozilijuan@126.com; cwang1@cdc.gov

${ }^{1}$ Beijing Center for Disease Control and Prevention, Beijing, China

${ }^{5}$ Centers for Disease Control and Prevention, Atlanta, GA, USA

Full list of author information is available at the end of the article
}

lasting more than 90 days after rash healed. Risk of PHN is very low among persons younger than age 40 but increases with age [1]. HZ frequently occurs on the thoracic and lumbar dermatomes, but the involvement of the eye (HZ ophthalmicus) may lead to serious outcomes and even blindness [2]. Approximately one out three people will develop $\mathrm{HZ}$ in their lifetime, and $\mathrm{HZ}$ incidence sharply increases after 50 years of age [3, 4].

Waning of cell-mediated immunity (CMI) is the main known determinant for $\mathrm{HZ}$, and factors associated with decline in CMI against VZV have been linked with HZ; these factors include advanced age, immunosuppression, decreased exposure to varicella, and certain chronic conditions $[5,6]$. The racial differences in $\mathrm{HZ}$ incidence indicate that host-genetic factors might be a risk factor 
for HZ [7]. Family history, often called the first genetic test, was found to be associated with $\mathrm{HZ}$ in several hospital-based, case control studies that also demonstrated a dose response relationship where the dose was number of relatives who have had HZ [8-12]. To date, only one study has examined family history of $\mathrm{HZ}$ with risk of developing PHN and found no association [13], and no study has assessed the role of family history for other HZ associated outcomes. To further examine the association of family history with $\mathrm{HZ}$ and associated outcomes, we carried out a population-based, matched, case control study in Beijing, China.

\section{Methods}

\section{Identification and enrollment of study subjects}

From December 2012 to March 2013, a cross-sectional, population survey was conducted to assess $\mathrm{HZ}$ disease burden in three districts of Beijing area: Xicheng was located in the urban heart of Beijing, Changping located in the north suburb, and Miyun located further northeast in a rural area. A two-step sampling algorithm was used to identify case-patients for the study. First, for each district, each city was categorized according to the varicella incidence during 2007-2011 into one of three groups (high, medium, and low), with a similar number of cities falling within each stratum. One city was randomly selected from each stratum, therefore, nine cities were sampled; eight agreed to participate. Second, one community/village was randomly selected from each of the eight participating cities. All residents who had lived in the area for at least six months during December 1, 2011 to November 30, 2012 were eligible to be study participants. All eligible participants of the community/village were contacted and interviewed faceto-face until reaching the target of 15,000 participants per community/village. The adjacent community/village would be enrolled if the first community/village had less than 15,000 participants enrolled in each city. An HZ case was defined as: 1) a diagnosis of $\mathrm{HZ}$ made by a medical provider (confirmed by review of medical records), or 2) if care was not sought, self-diagnosis of $\mathrm{HZ}$ based on the presence of clustered blisters on one dermatome with pain, itch, and hypersensitivity, during December 1, 2011 and November 30, 2012.

For each identified case-patient, three, age-matched ( \pm 5 years) controls were randomly selected from the residents who had never had $\mathrm{HZ}$ and who lived in the same community or village as the case-patient.

\section{Data collection}

Both case-patients and controls were interviewed using a standard form that collected data on sociodemographic characteristics and chronic conditions. Further information on $\mathrm{HZ}$ characteristics was collected from the case- patients, including the date of rash onset, whether they had a prior episode of HZ (recurrent HZ), pain severity (no or mild pain, moderate pain with little limitation of daily activities, and severe pain with important limitation of daily activities), and duration of pain after rash healed. PHN was defined as pain persisting 90 days or more after HZ rash healed [14]. Data on family history of HZ were collected for both case-patients and controls and included whether the subjects were aware of any family members/ relatives who ever had $\mathrm{HZ}$ and the relationship to the subject interviewed, which was used to determine the degree of blood relation (first degree vs. non-first degree relative).

\section{Statistical analyses}

Conditional logistic regression was used to assess the association of family history with HZ. We also examined the association of family history with $\mathrm{HZ}$ associated outcomes such as recurrent or primary HZ, HZ with different pain severity, or HZ with and without PHN. Since $\mathrm{HZ}$ is more likely to occur in females, the associations of family history with $\mathrm{HZ}$ were further examined in males and females, respectively. To maximize the accuracy of family history data, we restricted the analysis to first degree relatives only (defined as parents, offspring, and siblings) considering that reports of $\mathrm{HZ}$ occurrence among the first degree relatives were less subject to recall bias (because of more and closer interactions) and to information bias (subjects were more likely to be aware of occurrence of $\mathrm{HZ}$ among first degree relatives). Subjects who reported only a non-first degree relative with $\mathrm{HZ}$ were classified as not having a family history of HZ ( 6 case-patients and 6 controls).

The distribution of categorical or continuous sociodemographic factors between cases and controls were examined with Mantel-Haenszel chi-square or student t-test, respectively. The trend test was used to assess the association of family history with different $\mathrm{HZ}$ outcomes with multiple levels (e.g., dose response), such as primary and recurrent $\mathrm{HZ}, \mathrm{HZ}$ with and without PHN, and $\mathrm{HZ}$ with different pain severities. All analyses were performed with SAS version 9.3 (SAS Inc., Cary, NC).

Beijing Center for Disease Control and Prevention Ethics Committee on Human Subjects reviewed and approved the project.

\section{Results}

\section{Characteristics of study subjects}

A total of 905 subjects (227 case-patients and 678 age matched controls) were enrolled. The median age of subjects was 54.4 years (range: 11.1-85.5 years) and more than half were female $(486,53.7 \%)$. The majority of subjects were local residents $(799,88.4 \%)$, had less than high school education (604, 66.7\%), were farmers 
(483, 53.4\%) and had no underlying medical conditions $(718,79.3 \%)$. Among those with underlying medical conditions, hypertension was the most common condition $(108,57.8 \%)$, followed by diabetes (43, 23.0\%) and cardiovascular disease (18, 9.6\%). One subject had an organ transplant, one had uremia, one had cancer, and one was on immunosuppressive medication. There were no differences between casepatients and controls with respect to sociodemographic and medical characteristics (Table 1). For HZ case-patients, the median duration of pain was 20 days (range: 1-365 days), and the majority of $\mathrm{HZ}$ patients had moderate or severe pain (160, 70.5\%); 11 (4.8\%) developed PHN. HZ case-patients with PHN did not differ from those without PHN by age $(P=0.13)$, sex $(P=0.35)$, or underlying medical conditions $(P=1.0)$. A total of 26 subjects (11.5\%) experienced recurrent HZ. There was no difference between case-patients with primary and recurrent $\mathrm{HZ}$ by age $(P=0.40)$, sex $(P=0.28)$, or underlying medical conditions $(P=0.15)$. A total of $18(7.9 \%) \mathrm{HZ}$ case-patients were self-diagnosed with no difference between self-

Table 1 Distribution of Sociodemographic Factors between the Herpes Zoster Case-Patients and Controls

\begin{tabular}{|c|c|c|c|}
\hline & Case-Patients, n (\%) & Controls, n (\%) & \\
\hline & $N=227$ & $N=678$ & $P$ value \\
\hline Sex & & & 0.53 \\
\hline Male & $101(44.5)$ & $318(46.9)$ & \\
\hline Female & $126(55.5)$ & $360(53.1)$ & \\
\hline Age (years) & & & 0.92 \\
\hline$<40$ & $47(20.7)$ & $140(20.7)$ & \\
\hline $40-49$ & $45(19.8)$ & $138(20.4)$ & \\
\hline $50-59$ & $55(24.2)$ & $173(25.5)$ & \\
\hline $60-69$ & $54(23.8)$ & $142(20.9)$ & \\
\hline$\geq 70$ & $26(11.5)$ & $85(12.5)$ & \\
\hline Education & & & 0.17 \\
\hline Elementary school or less & $78(34.3)$ & $233(34.3)$ & \\
\hline Middle school & $62(27.3)$ & $231(34.1)$ & \\
\hline High school & $51(22.5)$ & $133(19.6)$ & \\
\hline College and above & $36(15.9)$ & $81(12.0)$ & \\
\hline Residency & & & 0.93 \\
\hline Local resident & $201(88.6)$ & $598(88.3)$ & \\
\hline Mobile population & $26(11.5)$ & $79(11.7)$ & \\
\hline Nationality & & & 0.16 \\
\hline Han & $215(94.7)$ & $655(96.8)$ & \\
\hline Other & $12(5.3)$ & $22(3.3)$ & \\
\hline Profession & & & 0.45 \\
\hline Farmer & $117(51.5)$ & $366(54.0)$ & \\
\hline Worker & $31(13.7)$ & $63(9.3)$ & \\
\hline Teacher & $4(1.8)$ & $11(1.6)$ & \\
\hline Healthcare worker & $0(0.0)$ & $7(1.0)$ & \\
\hline Government employee & $9(4.0)$ & $16(2.4)$ & \\
\hline Retired & $25(11.00$ & 79 (11.7) & \\
\hline Student & $1(0.4)$ & $4(0.6)$ & \\
\hline Unemployed & $12(5.3)$ & $44(6.5)$ & \\
\hline Other & $28(12.3)$ & $88(13.0)$ & \\
\hline Underlying medical condition & & & 0.25 \\
\hline Yes & $53(23.4)$ & $134(19.8)$ & \\
\hline No & 174 (76.7) & $544(80.2)$ & \\
\hline
\end{tabular}


diagnosed $\mathrm{HZ}$ and $\mathrm{HZ}$ diagnosed by medical providers by age $(P=0.17)$, sex $(P=0.62)$, or underlying medical conditions $(P=0.38)$.

\section{Family history and $\mathrm{HZ}$ and associated outcomes}

Overall, HZ case-patients were 2.4 times more likely to report a family history of $\mathrm{HZ}$ (among the first degree relatives) than their matched controls $(P=0.002)$ (Table 2$)$. The strength of association between family history and risk of $\mathrm{HZ}$ in males was almost twice that of females (3.3 vs. 1.7) (Table 3). There were only two case-patients with PHN and family history of HZ. Compared with the controls, case-patients with PHN were six times more likely to report a family history of HZ, though not statistically significant $(P=0.14)$, and case-patients with $\mathrm{HZ}$ without PHN were 2.3 times more likely to report family history $(P=0.006)$. In addition, case-patients with recurrent HZ were nine times more likely to report a family history $(P=0.05)$, while case-patients with primary $\mathrm{HZ}$ were around two times more likely to report a family history when compared with controls $(P=0.01$ and $P<0.001$ trend). Furthermore, compared with controls, HZ casepatients with moderate or severe pain were three times more likely to report a family history of $\mathrm{HZ}(P<0.001)$, while no difference was found for case-patients with mild or no pain $(P=0.72)$ (Table 2$)$. We did not examine the association of having more than one relative with $\mathrm{HZ}$ due to lack of data; there were only one case-patient and four controls who reported family history of $\mathrm{HZ}$ in more than one relative.

\section{Discussion}

Our study provides further evidence that family history is associated with HZ. Additionally, we found that association of family history of $\mathrm{HZ}$ was stronger among recurrent $\mathrm{HZ}, \mathrm{HZ}$ with $\mathrm{PHN}, \mathrm{HZ}$ with moderate or severe pain, and males.

The strength of the association between family history and $\mathrm{HZ}$ in our study $(\mathrm{OR}=2.4)$ is in the range of reported strength of association between family history and $\mathrm{HZ}$ from five other case control studies, three from the US and one from Iran and France (OR ranging from 1.7 to 6.6), even though hospital controls were used for all these five studies [8-12] Some of these studies examined the association of first degree relatives and found the strength of association ranged from 1.9 to 4.9 [8-10, 12], but they were inconsistent on the association of non-first degree relative with $\mathrm{HZ}$, range from no association [12] to strong association $(\mathrm{OR}=4.3$ and 4.8 , respectively) $[9,10]$. Albeit consensus has been reached on the association of family history and HZ [15], no study examined the strength of association in different races (as an indicator for differences in genetic predisposition), even though racial differences in $\mathrm{HZ}$ incidence are well documented [7]. More studies are needed to examine the effect of family history in $\mathrm{HZ}$ by race.

We also found a family history of $\mathrm{HZ}$ was more strongly associated with recurrent $\mathrm{HZ}$ than primary $\mathrm{HZ}$. This finding may indicate that those with recurrent $\mathrm{HZ}$ have a higher genetic predisposition for HZ. There are reports on genetic susceptibility for other recurrent infections such as upper respiratory tract infections and genital chlamydia infection $[16,17]$, in which the same immunogenetic factors as reported for $\mathrm{HZ}$ occurrence (IL-10 polymorphism) were implicated $[18,19]$. The proportion of recurrent $\mathrm{HZ}$ among case-patients in our study were similar to reoccurrence in other studies that also used self-reported HZ [20].

In addition, we found that family history was more strongly associated with $\mathrm{HZ}$ with moderate or severe pain than with mild or no pain. HZ-related pain intensity was associated with the duration of HZ-related pain $[21,22]$, with longer duration of HZ-related pain linked to increased risk of recurrent $\mathrm{HZ}$ [23]. As in a previous report [13], we did not detect a statistically significant association between family history of $\mathrm{HZ}$ and $\mathrm{PHN}$, but the strong association we found amongst the small

Table 2 Association of Family History with Herpes Zoster with Different Characteristics

\begin{tabular}{|c|c|c|c|c|c|}
\hline \multirow{2}{*}{$\begin{array}{l}\text { HZ with different } \\
\text { characteristics }\end{array}$} & \multicolumn{2}{|c|}{ Family history $^{a}$} & \multirow{2}{*}{$\begin{array}{l}\text { Odds ratio ( } 95 \% \\
\text { confidence interval) }\end{array}$} & \multirow[b]{2}{*}{$P$ value } & \multirow{2}{*}{$\begin{array}{l}P \text { value for } \\
\text { trend test }\end{array}$} \\
\hline & Yes, n (\%) & No, n (\%) & & & \\
\hline Controls & $33(4.9)$ & $645(95.1)$ & Reference & & \\
\hline All HZ case-patients & $24(10.6)$ & $203(89.4)$ & $2.4(1.4-4.3)$ & 0.002 & NA \\
\hline $\mathrm{HZ}$ with PHN & $2(18.2)$ & $9(81.8)$ & $6.0(0.5-66.2)$ & 0.14 & 0.002 \\
\hline $\mathrm{HZ}$ without PHN & $22(10.2)$ & $194(89.8)$ & $2.3(1.3-4.2)$ & 0.006 & \\
\hline Recurrent HZ & $4(15.4)$ & $22(84.6)$ & $9.4(1.0-88.5)$ & 0.05 & 0.005 \\
\hline Primary HZ & $20(10.0)$ & $181(90.0)$ & $2.2(1.2-3.9)$ & 0.01 & \\
\hline $\mathrm{HZ}$ with moderate/severe pain & $21(13.1)$ & $139(86.9)$ & $3.2(1.7-6.0)$ & $<0.001$ & $<0.001$ \\
\hline $\mathrm{HZ}$ with mild or no pain & $3(4.5)$ & $64(95.5)$ & $0.8(0.2-3.3)$ & 0.72 & \\
\hline
\end{tabular}

$\mathrm{HZ}$ herpes zoster; ${ }^{a}$ defined as history of $\mathrm{HZ}$ among first degree relatives (i.e., parents, offspring, siblings) 
Table 3 Different Strength of Association between Family History and Herpes Zoster by Sex ${ }^{\text {a }}$

\begin{tabular}{|c|c|c|c|c|}
\hline & \multicolumn{2}{|c|}{ Family history } & \multirow{2}{*}{$\begin{array}{l}\text { Odds ratio } \\
\text { (95\% confidence interval) }\end{array}$} & \multirow[b]{2}{*}{$P$ value } \\
\hline & Yes, n (\%) & No, n (\%) & & \\
\hline \multicolumn{5}{|l|}{ Male participants } \\
\hline HZ case-patients & $11(64.7)$ & $90(38.1)$ & $3.3(1.1-10.1)$ & \multirow[t]{2}{*}{0.04} \\
\hline Controls & $6(35.3)$ & $146(61.9)$ & Reference & \\
\hline \multicolumn{5}{|l|}{ Female participants } \\
\hline $\mathrm{HZ}$ case-patients & $13(46.4)$ & $113(36.8)$ & $1.7(0.7-4.0)$ & \multirow[t]{2}{*}{0.22} \\
\hline Controls & 15 (53.6) & $194(63.2)$ & Reference & \\
\hline
\end{tabular}

$\mathrm{HZ}$ herpes zoster; ${ }^{\mathrm{a}}$ controls with discordant sex from the matched case were removed from the analysis, leading to reduced number of controls included in this stratified analysis

number of PHN case-patients in our study warrant further study with a sufficient sample size, not to mention the scarcity of assessment on family history in PHN. In addition, we found effect modification by sex on family history association with HZ, with family history having a stronger effect on HZ risk in males [24]. Further studies are needed to verify the effect of sex on the association of family history and $\mathrm{HZ}$ risk.

Several limitations should be taken into account when interpreting the results of our study. Recall bias regarding family members with $\mathrm{HZ}$ might be differential between cases and controls. We attempted to minimize the recall bias by restricting the analysis to first-degree relatives; however, this bias is hard to eliminate. We included self-diagnosed HZ which could potentially increase the misclassification of $\mathrm{HZ}$ and weaken the association of family history with HZ risk. However, the proportion of self-diagnosed HZ was low and it has been found that self-reported HZ had high consistency with physician diagnosis in other populations [25]. Another limitation of using only first-degree relatives to define family history was that it reduced the number of relatives with family history, and made us unable to assess a dose-response relationship by the number of family members with a family history of $\mathrm{HZ}$ as in prior reports.

\section{Conclusions}

In summary, our study found that family history of $\mathrm{HZ}$ was associated with $\mathrm{HZ}$ occurrence. We also found that a family history of $\mathrm{HZ}$ was more strongly associated with recurrent $\mathrm{HZ}$ than primary $\mathrm{HZ}$ and $\mathrm{HZ}$ with moderate or severe pain than with no or mild pain. Given the availability of effective $\mathrm{HZ}$ vaccines $[21,26]$, vaccination of persons with risk factors for $\mathrm{HZ}$ or more severe $\mathrm{HZ}$ may be an important approach to either prevent $\mathrm{HZ}$ or limit suffering in these patients.

\section{Abbreviations}

CMI: Cell-mediated immunity; HZ: Herpes zoster; OR: Odds ratio; PHN: Postherpetic neuralgia; VZV: Varicella zoster virus
Acknowledgements

We thank the participants of our study and are indebted to the staff of Xicheng, Changping, and Miyun District CDCs for their coordination and field work and Ms. Jessica Allen for editorial assistance.

\section{Funding}

This project was funded by Beijing Center for Disease Control and Prevention.

\section{Availability of data and materials}

Data supporting our findings is contained within the manuscript; any additional data will be shared upon request.

\section{Authors' contributions}

LS, LL, XPang, CW conceived and designed the study. JL, HW, MS, XPeng, and FY involved in the study design and protocol development. FY, HW, MS, XPeng, and CW involved data analysis and interpretation of data. $L S, L L, J L$ and CW prepared the first draft of the paper. MM, XPang and CW involved in writing the final draft. All authors contributed to revise the draft, and read and approved the final manuscript.

\section{Competing interests}

The authors declare that they have no competing interests.

Consent for publication

Not applicable.

Ethics approval and consent to participate

Beijing Center for Disease Control and Prevention Ethics Committee on Human Subjects reviewed and approved the project. All subjects in this study gave their informed consent to participate.

\section{Disclaimer}

The findings and conclusions in this report are those of the authors and do not necessarily represent the official position of the Centers for Disease Control and Prevention.

\section{Publisher's Note}

Springer Nature remains neutral with regard to jurisdictional claims in published maps and institutional affiliations.

\section{Author details}

${ }^{1}$ Beijing Center for Disease Control and Prevention, Beijing, China. ${ }^{2}$ Xicheng District Center for Disease Control and Prevention, Beijing, China.

${ }^{3}$ Changping District Center for Disease Control and Prevention, Beijing,

China. ${ }^{4}$ Miyun District Center for Disease Control and Prevention, Beijing,

China. ${ }^{5}$ Centers for Disease Control and Prevention, Atlanta, GA, USA. 
Received: 15 October 2016 Accepted: 21 April 2017

Published online: 09 May 2017

\section{References}

1. Yawn BP, Gilden D. The global epidemiology of herpes zoster. Neurology. 2013;81(10):928-30.

2. Grose C. Stroke after varicella and zoster ophthalmicus: another indication for treatment and immunization. Pediatr Infect Dis J. 2010;29(9):868-9.

3. Oxman MN. Zoster vaccine: current status and future prospects. Clin Infect Dis. 2010;51(2):197-213.

4. Yawn BP, Saddier P, Wollan PC, St Sauver JL, Kurland MJ, Sy LS. A populationbased study of the incidence and complication rates of herpes zoster before zoster vaccine introduction. Mayo Clin Proc. 2007;82(11):1341-9.

5. Johnson RW, Alvarez-Pasquin MJ, Bijl M, Franco E, Gaillat J, Clara JG, Labetoulle M, Michel JP, Naldi L, Sanmarti LS, et al. Herpes zoster epidemiology, management, and disease and economic burden in Europe: a multidisciplinary perspective. Ther Adv Vaccines. 2015;3(4):109-20.

6. Forbes HJ, Thomas SL, Smeeth L, Clayton T, Farmer R, Bhaskaran K, Langan $\mathrm{SM}$. A systematic review and meta-analysis of risk factors for postherpetic neuralgia. Pain. 2016;157(1):30-54

7. Schmader K, George LK, Burchett BM, Hamilton JD, Pieper CF. Race and stress in the incidence of herpes zoster in older adults. J Am Geriatr Soc 1998;46(8):973-7.

8. Hernandez PO, Javed S, Mendoza N, Lapolla W, Hicks LD, Tyring SK. Family history and herpes zoster risk in the era of shingles vaccination. J Clin Virol. 2011;52(4):344-8.

9. Hicks LD, Cook-Norris RH, Mendoza N, Madkan V, Arora A, Tyring SK. Family history as a risk factor for herpes zoster: a case-control study. Arch Dermatol. 2008;144(5):603-8.

10. Ansar A, Farshchian M, Ghasemzadeh M, Sobhan MR. Association between family history and herpes zoster: a case-control study. J Res Health Sci. 2014; 14(2):111-4.

11. Lasserre A, Blaizeau F, Gorwood P, Bloch K, Chauvin P, Liard F, Blanchon T, Hanslik T. Herpes zoster: family history and psychological stress-case-control study. J Clin Virol. 2012;55(2):153-7.

12. Marin M, Harpaz R, Zhang J, Wollan P, Bialek S, Yawn B. Risk factors for herpes zoster among adults. Open Forum Infect Dis. 2016;3(3):1-7.

13. Gatti A, Pica F, Boccia MT, De Antoni F, Sabato AF, Volpi A. No evidence of family history as a risk factor for herpes zoster in patients with post-herpetic neuralgia. J Med Virol. 2010;82(6):1007-11.

14. Sampathkumar P, Drage LA, Martin DP. Herpes zoster (shingles) and postherpetic neuralgia. Mayo Clin Proc. 2009;84(3):274-80.

15. Lai YC, Yew YW. Risk of herpes zoster and family history: a meta-analysis of case-control studies. Indian J Dermatol. 2016;61(2):157-62.

16. Zehsaz F, Farhangi N, Monfaredan A, Tabatabaei Seyed M. IL-10 G-1082A gene polymorphism and susceptibility to upper respiratory tract infection among endurance athletes. J Sports Med Phys Fitness. 2015;55(1-2):128-34.

17. Wang C, Tang J, Geisler WM, Crowley-Nowick PA, Wilson CM, Kaslow RA. Human leukocyte antigen and cytokine gene variants as predictors of recurrent Chlamydia trachomatis infection in high-risk adolescents. J Infect Dis. 2005;191(7):1084-92.

18. Cho JW, Shin DH, Lee KS. Polymorphism of the IL-10 gene is associated with susceptibility to herpes zoster in Korea. J Dermatol Sci. 2007:45(3):213-5.

19. Haanpaa M, Nurmikko T, Hurme M. Polymorphism of the IL-10 gene is associated with susceptibility to herpes zoster. Scand J Infect Dis. 2002;34(2): 112-4.

20. Bowsher D. The lifetime occurrence of herpes zoster and prevalence of post-herpetic neuralgia: a retrospective survey in an elderly population. Eur J Pain. 1999;3(4):335-42.

21. Oxman MN, Levin MJ, Johnson GR, Schmader KE, Straus SE, Gelb LD, Arbeit RD, Simberkoff MS, Gershon AA, Davis LE, et al. A vaccine to prevent herpes zoster and postherpetic neuralgia in older adults. N Engl J Med. 2005; 352(22):2271-84

22. Dworkin RH, Johnson RW, Breuer J, Gnann JW, Levin MJ, Backonja M, Betts RF, Gershon AA, Haanpaa ML, McKendrick MW, et al. Recommendations for the management of herpes zoster. Clin Infect Dis. 2007;44(Suppl 1):S1-26.

23. Yawn BP, Wollan PC, Kurland MJ, St Sauver JL, Saddier P. Herpes zoster recurrences more frequent than previously reported. Mayo Clin Proc. 2011. 86(2):88-93.
24. Opstelten W, Van Essen GA, Schellevis F, Verheij TJ, Moons KG. Gender as an independent risk factor for herpes zoster: a population-based prospective study. Ann Epidemiol. 2006;16(9):692-5.

25. Schmader K, George LK, Newton R, Hamilton JD. The accuracy of self-report of herpes zoster. J Clin Epidemiol. 1994;47(11):1271-6.

26. Lal H, Cunningham AL, Godeaux O, Chlibek R, Diez-Domingo J, Hwang SJ, Levin MJ, McElhaney JE, Poder A, Puig-Barbera J, et al. Efficacy of an adjuvanted herpes zoster subunit vaccine in older adults. N Engl J Med. 2015;372(22):2087-96.

\section{Submit your next manuscript to BioMed Central and we will help you at every step:}

- We accept pre-submission inquiries

- Our selector tool helps you to find the most relevant journal

- We provide round the clock customer support

- Convenient online submission

- Thorough peer review

- Inclusion in PubMed and all major indexing services

- Maximum visibility for your research

Submit your manuscript at www.biomedcentral.com/submit
C Biomed Central 